\title{
A EVOLUÇÃO DOS REAGENTES QUÍMICOS COMERCIAIS ATRAVÉS DOS RÓTULOS E FRASCOS
}

\author{
Júlio Carlos Afonso* e Renata de Melo Aguiar
}

Departamento de Química Analítica, Instituto de Química, Universidade Federal do Rio de Janeiro, CP 68563, 21949-900 Rio de Janeiro - RJ

Recebido em 21/7/03; aceito em 5/1/04; publicado na web em 17/6/04

\begin{abstract}
THE EVOLUTION OF COMMERCIAL CHEMICALS VIA THEIR LABELS AND CONTAINERS. This work presents an evolution profile of labels and containers of commercial chemicals employed in laboratories since 1870. Most chemicals were made in Germany before the Second World War, after which many other manufacturers arrived on the Brazilian market. Northamerican products were dominant in the 1940s, but Brazilian chemicals have increased their participation along time. Labels presented increasingly more information, from originally simple names of the compounds at the beginning of the XXth century to the data presented today such as chemical formulae, safety regards and detailed chemical analysis. The raw material for container manufacturing also changed: glass was dominant until the 1950s, but nowadays plastic flasks are preferred whenever possible. Cork covers were replaced by screw caps. The diversity of commercial products also sharply increased with time, especially after the 1950s, following the many new and specific applications of chemicals for research and commercial purposes.
\end{abstract}

Keywords: laboratory chemicals; reagent evolution; containers' labels.

\section{INTRODUÇÃO}

Embora o uso de produtos químicos date das antigas civilizações, o surgimento da indústria química moderna é muito mais recente, pois é somente com o advento da I Revolução Industrial, por volta de 1800, que começou o provimento sistemático de produtos químicos para outras indústrias: álcali para fazer sabão, carbonato de sódio e sílica para manufatura de vidro, dentre outros exemplos ${ }^{1}$.

A noção de qualidade de um produto químico, ou seja, a capacidade daquele reagente cumprir a finalidade à qual se destina, é bastante antiga, embora nos primórdios da química comercial, isso fosse uma preocupação esporádica ${ }^{2,3}$. O florescimento da indústria química levou à necessidade de se ter algum tipo de avaliação da qualidade das matérias-primas usadas nos processos então empregados, talvez por razões econômicas: matérias-primas adulteradas significavam um sério prejuízo para a fábrica ${ }^{3}$. Desde meados do século XIX, já se tinha a opinião de que o rótulo de um produto químico deveria conter todas as informações de interesse, como ocorre com os produtos farmacêuticos ${ }^{2,4}$.

O desenvolvimento da análise titulométrica e a necessidade de produtos químicos de pureza controlada para aplicações na indústria química, na medicina e na farmácia levou à necessidade de desenvolver meios de testar esses materiais. Em 1857, apareceu um compêndio, "Os Dicionários para o Atlas Químico", onde testes qualitativos eram aplicados para a verificação da pureza de produtos comerciais. Isto era suficiente para constatar adulterações. Todavia, o grande salto na qualidade dos produtos químicos deu-se em 1888: o alemão Carl Krauch (1853-1934) preparou um livro sobre o assunto, "O Exame da Pureza dos Reagentes Químicos"'. Os testes ainda eram basicamente qualitativos, mas havia uma preocupação maior, isto é, não se buscava apenas verificar falsificações, mas também conferir a qualidade dos reagentes quanto à ausência de impurezas oriundas de suas matérias-primas e do processo de síntese. De fato, naquela época, havia uma proliferação indiscriminada de produtos com as expressões latinas purum, purissimum ou depuratum, mas

*e-mail: julio@iq.ufrj.br sem qualquer tipo de controle por parte dos fabricantes. Este feito veio a ser um dos fatores a justificar a fama da indústria química alemã no mercado consumidor ${ }^{7,8}$. Uma importante inovação foi a instalação de laboratórios de controle independentes, separados da área produtiva ${ }^{4,9,10}$, que tinham como meta a inspeção dos produtos sintetizados, bem como avaliar as matérias-primas que chegavam à fábrica. Em 1903, o conselho da "American Chemical Society (ACS)" iniciou estudos para estabelecer um padrão de especificações para reagentes químicos ${ }^{3}$. Em 1924, o comitê de reagentes da ACS publicou a primeira versão sobre especificações e procedimentos de análise de produtos químicos sendo, desde então, submetido a novas reedições e atualizações. Em 1911, na Inglaterra, foi publicada uma outra obra sobre a pureza de reagentes, "Reagentes Analíticos, Padrões e Testes" ${ }^{11}$ que, tal como a obra de Carl Krauch, teve diversas reedições, com atualizações.

Após a $2^{\mathrm{a}}$ Guerra Mundial, face à existência de especificações de diversos fabricantes e organismos, buscou-se uma unificação dos critérios, o que não foi obtido na prática ${ }^{3}$. A "International Organization for Standardization (ISO)", através de três normas de padronização e certificação para diversos reagentes comuns de laboratório $^{3}$ (1982, 1983 e 1987), buscou retomar a idéia de um critério internacional de padronização de produtos químicos.

Hoje em dia, antes da liberação de um lote de produto químico, este precisa ser submetido a uma bateria de testes e ensaios independentes, tanto mais quanto mais específico for o emprego em uma determinada área de pesquisa ou de desenvolvimento ${ }^{12}$.

A partir do acervo do Museu da Química Prof. Athos da Silveira Ramos (1906-2002), instalado no Instituto de Química da Universidade Federal do Rio de Janeiro, estudou-se em detalhe os cerca de 2400 produtos químicos comerciais catalogados, sob vários aspectos: procedência, tipo de frasco, detalhamento do rótulo e natureza do produto comercializado. Este acervo abrange os últimos 133 anos de ensino de química na cidade do Rio de Janeiro (1870-2003). Os resultados obtidos desta pesquisa são o objetivo deste trabalho, os quais servem para ilustrar como o progresso da química se refletiu na quantidade de produtos e na variedade de informações e maneiras de apresentar os mesmos, ao longo do tempo. 


\section{METODOLOGIA DE ANÁLISE DO MATERIAL}

A etapa primordial foi a datação dos reagentes, onde adotaramse duas estratégias: para aqueles fabricados a partir de 1921, a partir do número de lote impresso no rótulo, e segundo as orientações fornecidas pelas empresas fabricantes ${ }^{13}$, pode-se determinar o ano de fabricação do produto. No caso de produtos anteriores a 1921, recorreu-se a registros de compra de época ${ }^{14,15}$ e à comparação com fragmentos de antigos catálogos de insumos para laboratório ${ }^{9}$. Uma vez cumprida esta etapa, procedeu-se à análise do perfil evolutivo dos reagentes químicos, segundo as linhas gerais expostas ao final da Introdução.

\section{PERFIL DAS EMBALAGENS}

\section{A embalagem de vidro}

Nos exemplares datados do final do século XIX e dos primeiros anos do século XX, observa-se um dos símbolos do laboratório químico daquela época: o frasco de vidro sódico (fino e extremamente frágil ao choque e ao calor - Figura 1). A partir dos anos 1910, surgiram recipientes em vidro neutro, em substituição ao vidro sódico, mais resistente a impactos e ao aquecimento.

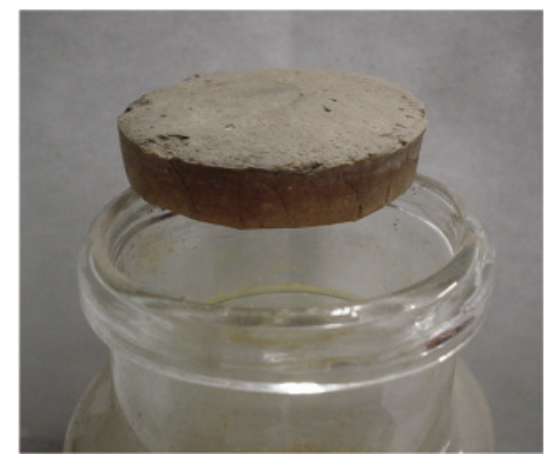

Figura 1. Embalagem típica de vidro sódico e a rolha de cortiça, final do século XIX

Como regra geral, a capacidade (expressa em $\mathrm{mL} \mathrm{ou} \mathrm{cm}^{3}$ ) era estampada na base do frasco, em números bem visíveis. Esta prática foi bastante utilizada até os anos 1950. As capacidades iam de 10 até $3000 \mathrm{~mL}$, sendo as mais comuns: 30, 50, 100, 150, 200, 250 e $500 \mathrm{~mL}$.

Até os anos 1950, o vidro era praticamente a matéria-prima única para a embalagem. As cores mais comuns eram a transparente e a marrom (âmbar), estas últimas sempre encontradas quando destinadas ao acondicionamento de produtos sensíveis à luz (sais de prata, iodetos, reagentes orgânicos, etc).

\section{A embalagem de plástico}

A análise do acervo mostra que os primeiros exemplares de frascos deste tipo são dos anos 1920: feitos de baquelite ou de ebonite, eram empregados no acondicionamento do ácido fluorídrico (HF), o qual ataca o vidro (Figura 2).

A partir da década de 1960, o plástico passou a ser uma opção de material do frasco, em contraposição ao tradicional vidro ${ }^{9,16}$. Neste particular, deve-se mencionar que as ampolas de soluções padronizadas passaram a ser feitas de plástico. Isso é particularmente evidente para o caso de soluções alcalinas (hidróxido de sódio, carbonato de sódio etc), onde o vidro era lentamente atacado por estas soluções, contaminando-as (Figura 3). Ao que tudo indica, a partir

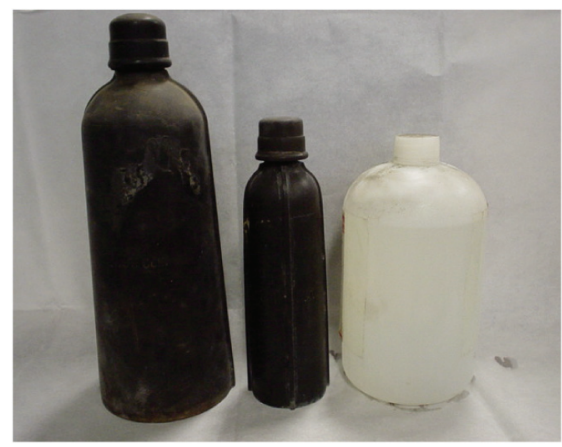

Figura 2. O acondicionamento do ácido fluorídrico: frasco de ebonite, 1920 (à esquerda); frasco de baquelite, 1926 (ao centro); frasco de polietileno, 1996 (à direita)

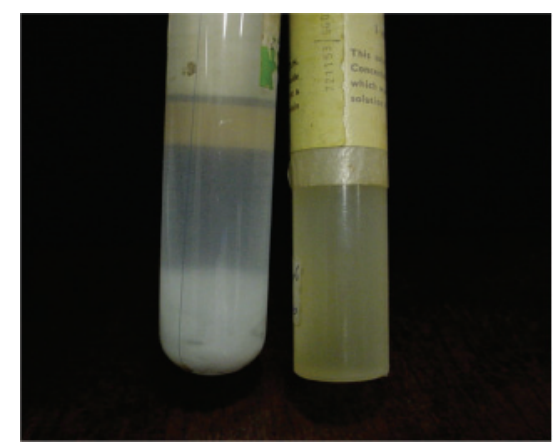

Figura 3. A ampola de $\mathrm{NaOH}\left(0,1 \mathrm{~mol} \mathrm{~L}^{-1}\right)$ em embalagem de vidro (1962, à esquerda) e em embalagem plástica (1972, à direita). Notar a formação de depósito branco na embalagem da esquerda, fruto do ataque da base ao vidro

da década de 1980 o plástico superou o vidro como opção de embalagem.

A substituição do vidro pelo plástico não deve ser encarada apenas como uma opção estética, mas sobretudo de segurança: reduz-se o peso bruto do material e minimiza-se o risco de acidentes caso o frasco caia no chão. A partir dos anos 1960, o barateamento do preço dos plásticos mais comuns hoje (polietileno, PVC poliestireno etc) permitiu que as embalagens deste material tivessem competitividade ${ }^{17}$. Hoje o vidro limita-se aos casos de acondicionamento de solventes orgânicos, ácidos (exceto o HF), hidróxido de amônio e materiais incompatíveis quimicamente com os plásticos.

\section{A tampa e a vedação da embalagem}

A vedação é um item de óbvia importância para assegurar a qualidade do produto. Nos primórdios da química comercial, um item característico era a rolha de cortiça (Figura 1). Esta era envolvida juntamente com a borda da embalagem por uma folha metálica (similar ao caso das garrafas de vinho atuais), geralmente de chumbo, sendo esta ainda envolvida por um selo de papel contendo a logomarca da empresa ou uma folha de papel manteiga (Figura 4). No caso de produtos higroscópicos e sensíveis ao oxigênio, a rolha ainda era envolvida por uma camada de parafina, como reforço à vedação. $\mathrm{O}$ sucesso dessa medida pode ser atestado por dois reagentes sensíveis ao ar e à luz, anilina (1914) e piridina (1913), que ainda se apresentam como líquidos incolores (ambos também embalados em frasco de cor âmbar). Todavia, isto não foi regra geral, pois alguns reagentes higroscópicos e deliqüescentes, como os cloretos de cromo (chromium chloratum, 1920) e de cobre (cuprum chloratum, 1929), que nunca foram abertos, eram em parte soluções saturadas dos respectivos sais, 

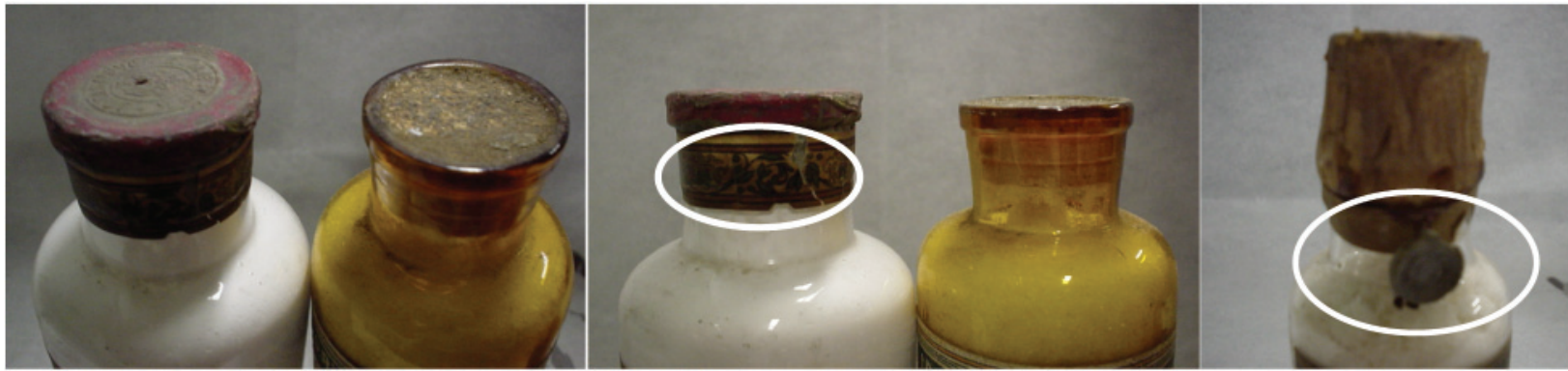

Figura 4. Os frascos, além da rolha, contêm um lacre (em vermelho nas fotos à esquerda e ao centro) e uma fita de papel em torno do gargalo do frasco (foto ao centro), ou então a rolha era envolvida em folha de papel presa ao frasco com um barbante (foto à direita)

sinal que a umidade havia atravessado a rolha com o tempo, por conta de rachaduras verificadas na estrutura da cortiça e na camada de parafina.

Havia produtos que não eram embalados da forma tradicional: substâncias fortemente reativas frente à cortiça e hidrolisáveis, como o tetracloreto de silício, o tetracloreto de titânio, o trióxido de enxofre e o cloreto de tionila, eram selados em ampola de vidro (Figura 5), normalmente de capacidade $10 \mathrm{~mL}$, indicando que se destinavam a uso único.

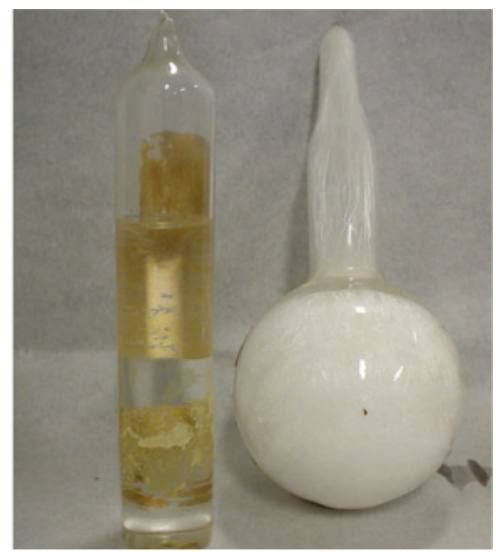

Figura 5. Dois produtos extremamente reativos frente à umidade selados em ampolas de vidro: tetracloreto de silício (à esquerda, 1920) e trióxido de enxofre (à direita, 1933)

Nos anos 1930, a tampa ainda era basicamente feita de cortiça; todavia, no final desta década, surgiram os primeiros frascos com tampa rosqueada de baquelite. Na década seguinte, essa tampa plástica passou a ser largamente empregada; assim, iniciava-se o fim da clássica associação entre a rolha de cortiça e o frasco de vidro.

A substituição da rolha de cortiça pela tampa rosqueada visava facilitar a abertura do frasco, minimizando também acidentes no momento da remoção da rolha e contaminações do produto por fragmentos de cortiça. Além disso, no caso de abrir o frasco diversas vezes, a vedação com a tampa rosqueada era mais efetiva, enquanto que a rolha perdia eficiência (fissuras, rachaduras, etc), aspecto particularmente crítico para produtos higroscópicos, oxidáveis e hidrolisáveis.

A vedação dos frascos com tampa rosqueada (Figura 6), inicialmente inexistente, passou a ser feita do seguinte modo: para reagentes sólidos, apunha-se um disco de papel prensado ajustado à abertura do frasco e à parte interna da tampa; contudo, ele tendia a se degradar com o abrir e fechar do recipiente, e a ser atacado por substâncias reativas e umidade. No caso dos líquidos, recorria-se à colocação de artefatos de plástico (polietileno, baquelite) ajustados na parte interna da tampa ou, então, à colocação de um vedante plástico que se ajustava sob pressão na abertura do frasco.

Na década de 1960, a vedação mereceu uma nova atenção especial dos fabricantes (Figura 6). Regra geral, ao se remover a tampa, observava-se um lacre que podia ser uma tampa plástica (produtos líquidos e sólidos higroscópicos, oxidáveis, hidrolisáveis ou muito tóxicos) ou um selo de papel aderido à abertura do recipiente (produtos sólidos estáveis frente ao ar).
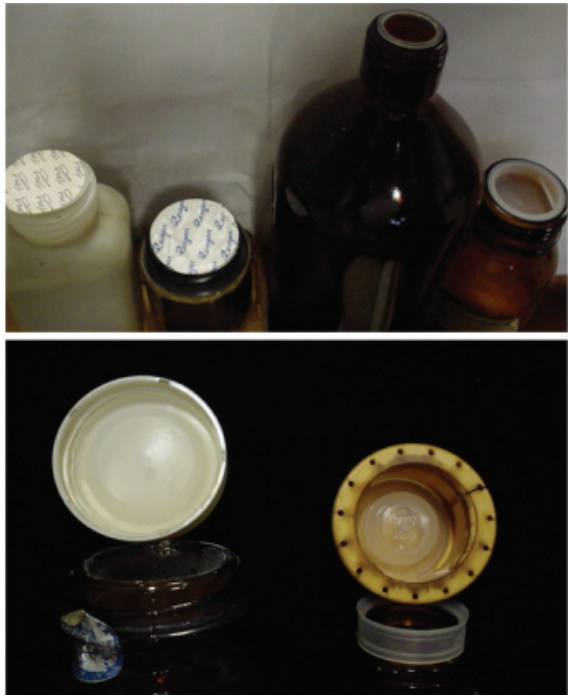

Figura 6. Alguns exemplos de vedação de reagentes: acima: reagentes sólidos (anos 1960) contendo um lacre branco colado à boca do recipiente, e reagentes líquidos (anos 1970) contendo um disco plástico que se ajusta à abertura do frasco por pressão; abaixo: reagentes líquidos (anos 1950) em cuja parte interna da tampa rosqueada apõe-se um vedante em plástico ajustado à abertura do recipiente

Mais recentemente, a preocupação com a segurança acabou por envolver o redesenho da tampa (vedação estanque, redução de desperdícios no momento da retirada do produto, etc).

\section{OS PRODUTOS QUÍMICOS}

\section{Apresentação dos produtos}

Os produtos ao final do século XIX e início do XX apresentavam, via de regra, uma aparência bastante grosseira (Figura 7). Na década de 1910, embora de granulometria bem mais fina que os materiais do período anterior, os produtos sólidos ainda apresentavam um aspecto relativamente grosseiro. Nos anos 1920, o aspecto visual dos sólidos comercializados já se assemelhava bastante ao que se verifica hoje em dia. 

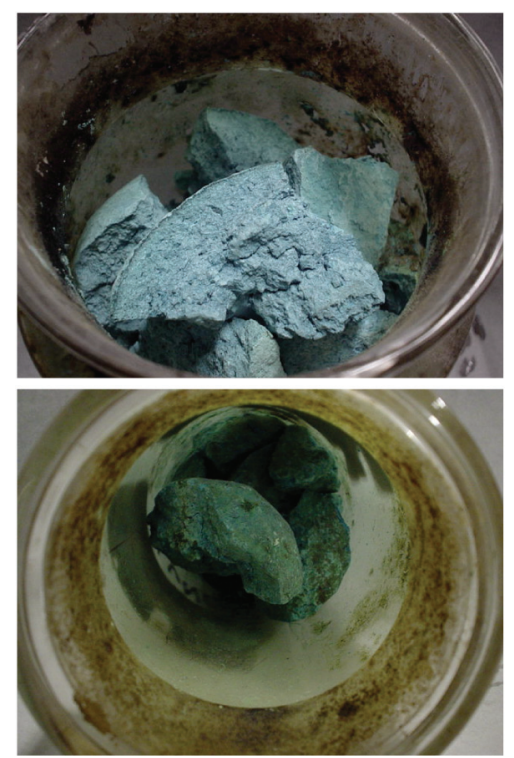

Figura 7. Arseniato de cobre (1877, acima) e acetato básico de cobre (1908, abaixo), mostrando o aspecto grosseiro dos mesmos, em contraste com a apresentação atual

É dessa década que se encontram no acervo as mais antigas soluções-padrão para titulometria, por exemplo: ácido arsenioso $\left(0,1 \mathrm{~mol} \mathrm{~L}^{-1}, 1922\right)$ e oxalato de sódio $\left(0,1 \mathrm{~mol} \mathrm{~L}^{-1}, 1928\right)$, em frascos de $500 \mathrm{~mL}$ ou de $1 \mathrm{~L}$, que tinham as características normais dos outros frascos de reagentes. Cabe destacar que esses produtos já eram comercializados há pelo menos uma década ${ }^{13}$. A partir dos anos 1940, popularizaram-se ampolas de soluções-padrão (inicialmente em vidro, mais tarde substituído pelo plástico), substituindo a apresentação anterior em embalagens destinadas aos reagentes comuns. Os volumes variavam de 10 a $50 \mathrm{~mL}$, indicativo de que as soluções ali contidas se destinavam a uso único, evitando eventuais contaminações decorrentes de manuseio quando essas alíquotas eram tomadas de frascos com capacidades maiores.

Ao que tudo indica, nas primeiras décadas do século XX, não havia uma distinção nítida entre acondicionamento de sólidos e de líquidos; o tipo de frasco e a rolha de cortiça eram os mesmos nos dois casos. A partir dos anos 1930 começou a se verificar uma certa distinção entre a apresentação de reagentes sólidos e líquidos: dentre estes, alguns continham uma rolha de vidro esmerilhado, mas o frasco era originalmente selado com uma rolha de borracha ou de cortiça (fator de segurança no transporte de produtos perigosos - amônia, soluções corrosivas, tóxicas, etc). Após a remoção desta é que a rolha de vidro era colocada sobre a abertura do frasco; isto também evitava que pedaços de borracha ou de cortiça caíssem no líquido (contaminando-o) no decorrer de sucessivas aberturas do frasco ${ }^{9,12}$.

Uma característica interessante era o modo de comercialização dos produtos líquidos: hoje em dia é rotina ver os produtos líquidos comercializados por volume (litro, mililitro), mas, no passado, esses reagentes eram comercializados por peso (gramas, quilogramas Figura 8), independentemente se a densidade do produto era maior ou menor que a da água, excetuando-se as soluções-padrão titulométricas. Aparentemente, só a partir dos anos 1940 é que a venda por volume se consagrou como opção básica, por questões práticas ${ }^{13}$.

\section{Variedade de produtos}

A análise dos produtos datados do período 1870-1900 mostra que quase todos correspondiam a sais simples inorgânicos ou então a produtos extraídos de fontes naturais (essencialmente corantes).

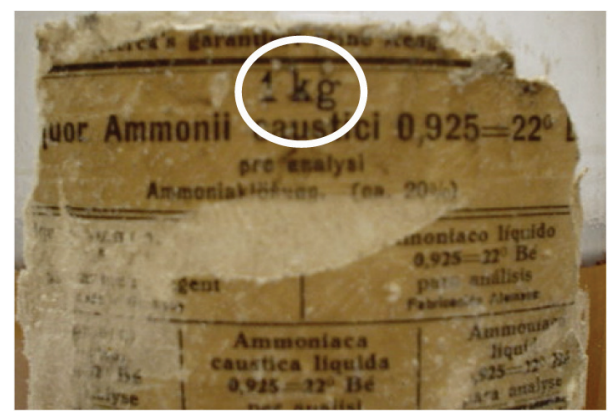

Figura 8. Exemplo de reagente líquido comercializado por peso: hidróxido de amônio $\left(d=0,925 \mathrm{~g} \mathrm{~mL}^{-1}\right)$, 1931. A embalagem contém $1 \mathrm{~kg}$ do produto

Nas duas décadas seguintes, os produtos naturais ainda continuavam a ter uma aparente forte participação, pois havia menções expressas a produtos "artificiais" (oriundos de síntese), como no exemplo mostrado na Figura 9.

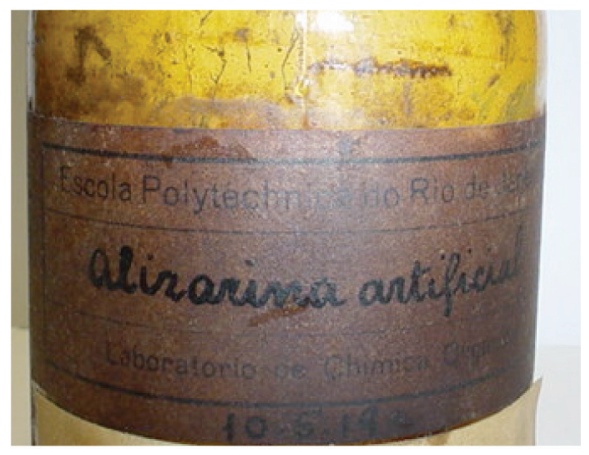

Figura 9. Alizarina artifical (1918), reagente da Escola Politécnica do Rio de Janeiro

Na década de 1950 verificou-se um grande aumento na variedade de produtos como, por exemplo, materiais para a área bioquímica e o surgimento das primeiras resinas de troca iônica comerciais (os exemplares mais antigos datam de 1956). Na década seguinte, a variedade de reagentes aumentou extraordinariamente por conta do surgimento de linhas de produtos para finalidades especiais: cromatográficas, bioquímicas, reagentes suprapuros, etc. A partir dos anos 1970, o aumento na diversificação de produtos deveu-se especialmente à oferta de produtos de química fina e solventes com aplicações específicas e controles de qualidade diferenciados em relação aos solventes comuns, face ao grande desenvolvimento da área de instrumentação analítica.

\section{Origem dos produtos}

Os reagentes mais antigos procedem basicamente da Alemanha ou da França ${ }^{15}$. Apesar de possíveis críticas e incertezas em função de algum consumo preferencial de certos produtos e de determinados fornecedores, é muito evidente a predominância dos reagentes alemães nos cursos e disciplinas da área química até antes da $2^{\mathrm{a}}$ Guerra Mundial (cerca de $75 \%$ do acervo até 1939 é composto por produtos alemães). Após a unificação (1870), a Alemanha adotou um sistema de ensino técnico combinando a pesquisa acadêmica, a pesquisa industrial e a formação profissional, vindo a ser a líder mundial na área química. As principais indústrias alemãs deste setor passaram de laboratórios familiares a grandes fábricas com centenas e, mais tarde, milhares de empregados. De um simples catálogo com menos de 1.000 produtos em 1860, várias empresas já dispunham de mais 
de 10.000 itens na virada para o século $X^{4,12}$. A ênfase dada à pesquisa aplicada em química fez com que em 1914 a indústria química alemã fosse responsável por $75 \%$ do mercado mundial de produtos químicos ${ }^{1}$, cuja preponderância perdurou até o início da $2^{\text {a }}$ Guerra Mundial. Além disso, até o final dos anos 1930, a indústria química alemã influenciou notavelmente a química no Brasil, em função de migrações, fuga de cérebros perseguidos pelo nazismo e absorção de mão-de-obra jovem alemã excedente no país natal ${ }^{18}$.

O rompimento das relações Brasil - Alemanha, em 1942, determinou a intervenção federal ${ }^{16}$ nas empresas de origem alemã no país; assim, praticamente desapareceram os reagentes alemães do mercado nacional, embora alguns deles tenham conseguido furar o bloqueio naval aliado e chegar ao país ${ }^{16}$ (no acervo os primeiros reagentes alemães pós-guerra datam de 1949). O mercado antes ocupado pela Alemanha foi principalmente transferido para os produtos químicos de origem norte-americana (mais de 50\% do acervo dos anos 1940), vindo a seguir os de procedência inglesa. $\mathrm{O}$ exame do acervo mostra que, nos anos 1950, parte do mercado brasileiro perdido para os Estados Unidos foi retomado pela indústria química européia em geral, mas sem jamais atingir a amplitude vista antes da $2^{\text {a }}$ Guerra Mundial.

Deve-se mencionar que nos anos 1940 surgiram reagentes feitos no Brasil por pequenas firmas (Figura 10). Salvo no caso de produtos de fontes naturais (corantes, óleos, resinas), não se encontrou nenhum produto químico manufaturado por empresas nacionais anterior a essa década. É interessante assinalar que, apesar da guerra ter favorecido a criação de empresas químicas nacionais, quase todas elas fecharam suas portas nos anos seguintes. Há um caso relatado ${ }^{19}$ referente a uma empresa que fabricava ampolas de solução-padrão para titulometria no início daquela década: de vida efêmera, sofreu a concorrência de produtos estrangeiros que eram considerados melhores que os fabricados aqui.

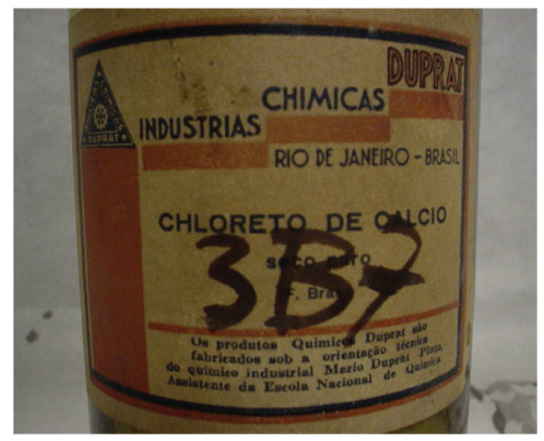

Figura 10. Um exemplo de reagente nacional dos anos 1940: "chloreto de cálcio" das "Indústrias Chimicas Duprat”, 1942

Por outro lado, durante a $2^{\text {a }}$ Guerra Mundial, houve falta de várias matérias-primas no Brasil, em contraste com a sobra de outras por dificuldades de transporte e comercialização. A partir daí, notou-se a necessidade de se contar no país, principalmente em São Paulo, com suprimento que não dependesse em grande parte do exterior $^{1}$. Deste modo, surgiram as primeiras instalações industriais (acetato e nitrato de celulose, papel e papelão, amônia, anidrido ftálico, fenol, ácido fórmico, etc). A indústria de produtos químicos orgânicos baseou-se fundamentalmente em etanol e acetileno até a montagem da Refinaria de Cubatão, em 1950, quando se deu o início da era petroquímica no Brasil ${ }^{1}$. A partir dos anos 1960, verificou-se uma tendência ao aumento da participação de produtos nacionais ao longo das décadas seguintes.

Nos anos 1980, algumas empresas químicas estrangeiras deixaram o Brasil, sendo representadas por terceiros nacionais. Algumas empresas brasileiras aumentaram consideravelmente a sua parcela no mercado, respondendo pelo aumento da participação de reagentes nacionais nessa década.

Ao final dessa década, a globalização determinou alterações dramáticas no perfil da indústria química no Brasil: muitas empresas nacionais tradicionais fecharam suas portas e as multinacionais deixaram praticamente de produzir no país; apesar dessa retração no parque químico nacional, algumas novas empresas aparecem para disputar este mercado.

\section{ANÁLISE DOS RÓTULOS}

\section{Linguagem de apresentação dos produtos}

Os nomes dos produtos químicos comerciais na virada do século XIX para o XX eram freqüientemente escritos em latim. Esta língua foi empregada como língua de identificação (principal ou secundária) de produtos químicos até o final dos anos 1960.

Nos anos 1920, os rótulos indicam que, além do latim, o nome do produto podia vir impresso em pelo menos um dos seguintes idiomas: alemão, espanhol, inglês, francês, italiano e português (Figura 11). Isso se deve a fatores comerciais ${ }^{13}$. Também foram identificados produtos feitos nessa época por empresas européias com rótulos em português (Figura 12). Este fato mostrava que o Brasil tinha uma posição econômica de importância no contexto latino-americano; estes reagentes foram enviados para revenda no país e em outros países da América do Sul ${ }^{4,9,10,12,16}$. Muitos desses reagentes contêm um rótulo no estilo art déco.

Como reflexo da ampliação do comércio mundial de produtos químicos, em meados dos anos 1930, diversos rótulos passaram a apresentar o nome do produto em chinês e japonês.

A grafia dos nomes químicos reflete as mudanças introduzidas no português escrito no século XX. Assim, até o início dos anos

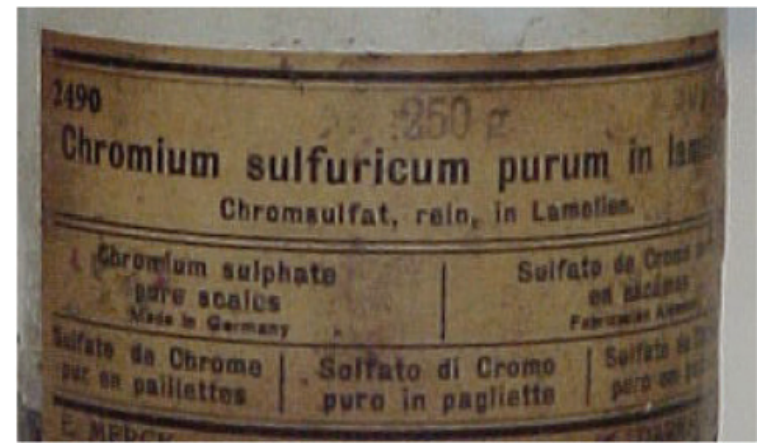

Figura 11. Sulfato de cromo(III) (chromium sulfuricum, 1926), mostrando no rótulo a identificação principal em latim e também em cinco outros idiomas (inglês, francês, espanhol, português e alemão)

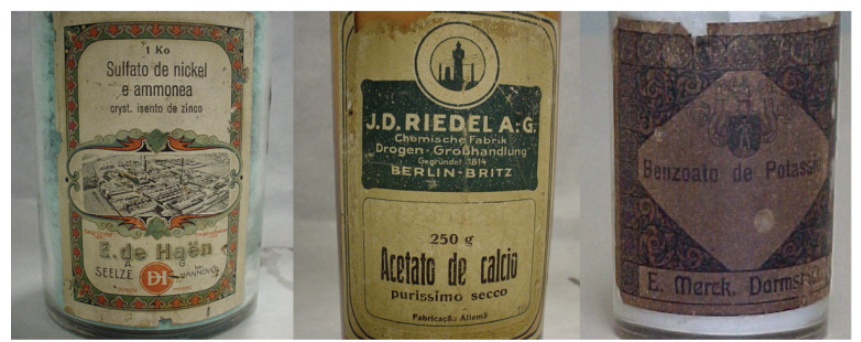

Figura 12. Reagentes com rótulos escritos em português: à esquerda, "sulfato de nickel e ammonea" (1924); ao centro, acetato de cálcio "puríssimo secco” (1928); à direita, benzoato de potássio (1927), em rótulo do estilo art déco 
1930, eram comuns expressões como "phosphato de baryo", "chlorureto de manganez", "bichromato de ammonio", "sulfureto de stroncio", "iodureto de nickel" etc (vide também Figura 10). Após as reformas ortográficas de 1931 e, especialmente, a de 1943 a grafia foi aos poucos assumindo a forma como hoje se conhece, mas é interessante assinalar que, nos anos 1950, ainda se encontravam frascos oriundos de fornecedores alemães com rótulos escritos em português antes das reformas acima mencionadas. Ao terminar a intervenção nas empresas de origem alemã no Brasil (em meados da década de 50), estas foram devolvidas aos seus donos originais e foi só aí que a matriz procedeu à atualização ortográfica do português dos produtos e catálogos em geral ${ }^{2,10,12,13,16}$.

Hoje, a identificação principal do reagente é na língua do país em que ele é fabricado, sendo comum figurar a denominação também em outros idiomas quando o produto pode ser exportado.

\section{Dados de descrição dos produtos}

Por volta de 1932 surgiu a fórmula química nos rótulos de alguns fabricantes. Antes, somente havia o nome do produto por extenso, mas o aparecimento da fórmula representou uma evolução notável em termos de detalhamento (Figura 13), permanecendo em uso até hoje. Identificava-se um produto pela sua fórmula quando as denominações apresentadas não eram compreensíveis no país onde o produto era comercializado ${ }^{13}$.

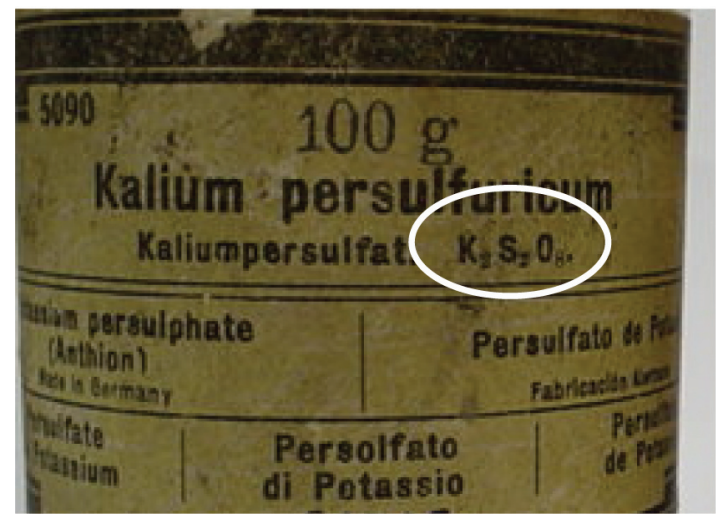

Figura 13. Persulfato de potássio (kalium persulfuricum, 1933), evidenciando a fórmula química do produto no rótulo

Na década seguinte, a indicação do "peso molecular" e de constantes físicas (pontos de fusão e ebulição, densidade, índice de refração) passaram a constar da descrição do produto; tratava-se de um meio cômodo de se obter os dados básicos do mesmo, facilitando, por exemplo, os cálculos de preparo de soluções ${ }^{13}$.

\section{Nomenclatura}

No início do século XX, a nomeação dos reagentes era um capítulo à parte, dada a variedade de denominações, reflexo da falta de sistematização em nível de nomenclatura.

Na comercialização de corantes e pigmentos, praticamente só se empregavam nomes triviais, às vezes bastante curiosos (amarelo indiano, verde de Paris, sombra de Colônia, verde de Londres, vermelho da Inglaterra, etc), situação essa que se estendia a alguns sais e óxidos como sal de Epson $\left(\mathrm{MgSO}_{4}\right)$, sal de $\mathrm{Mohr}\left[\left(\mathrm{NH}_{4}\right)_{2} \mathrm{Fe}\left(\mathrm{SO}_{4}\right)_{2}\right]$, sal de Seignette (tartarato de sódio e potássio), verde de Scheele (arseniato de cobre), colcotar (óxido férrico) e mínio $\left(\mathrm{Pb}_{3} \mathrm{O}_{4}\right)$. Expressões como "sequióxido de..." (óxidos com a fórmula geral $\mathrm{X}_{2} \mathrm{O}_{3}$ ), sulfato "neutro" de sódio $\left(\mathrm{Na}_{2} \mathrm{SO}_{4}\right)$ eram de uso corrente. $\mathrm{O}$ empre- go da palavra peróxido levava a interpretações errôneas: se as denominações peróxido de bário $\left(\mathrm{BaO}_{2}\right)$ ou de estrôncio $\left(\mathrm{SrO}_{2}\right)$ são corretas, o mesmo não se pode dizer das menções "peróxido de manganês" $\left(\mathrm{MnO}_{2}\right)$ ou "peróxido de chumbo" $\left(\mathrm{PbO}_{2}\right)$, onde o metal tem número de oxidação +4 e não +2 . Somente a partir dos anos 1950 é que o uso de nomes vulgares e denominações antiquadas começou a ceder lugar ao emprego de nomenclaturas oficiais. Isso se relaciona ao trabalho intensivo que a IUPAC vem realizando desde aquela ocasião ${ }^{3}$.

\section{Garantia de pureza dos produtos}

Apesar de já existirem preocupações quanto à pureza e à qualidade dos produtos químicos por parte das indústrias, os rótulos dos produtos comerciais das duas primeiras décadas do século XX ainda não incorporavam claramente esta postura nos rótulos. Nos anos 1910, alguns produtos apresentavam uma simples menção de garantia de qualidade por parte da empresa, com mensagens do tipo: "o fabricante X garante a qualidade deste reagente". Por volta de 1920, nas logomarcas das empresas, surgiram as expressões "Trade Mark" ou "Marca Registrada".

Somente em meados dos anos 1920 é que se observou em rótulos de alguns fabricantes a inclusão de um pequeno certificado de garantia. Por exemplo, no caso do "cuprum chloratum" (cloreto de cobre), de 1929, tem-se no português da época: "Este reagente tem sido analysado (...) e se evidenciou isento de impurezas insolúveis n'álcool, sulfatos, saes alcalinos, ferro, baryo e arsênico". Não havia nenhuma referência aos procedimentos de análise utilizados na caracterização dos reagentes mas, tratava-se de uma combinação de análises gravimétricas, volumétricas e titulométricas clássicas com procedimentos de análise qualitativa ${ }^{13}$.

Nos anos 1940 os rótulos dos reagentes norte-americanos exibiam boletim de garantia, com grande detalhamento quanto ao teor limite de impurezas (Figura 14), uma novidade em relação aos anos anteriores. Nesse aspecto, cabe destacar que os produtos nacionais daquela época não incorporavam esta postura (inclusive no que tange à adoção da tampa rosqueada), fato somente verificado de forma sistemática a partir dos anos 1960. Também vale a pena mencionar que desde meados dos anos 1930, 220 produtos fabricados na Inglaterra já exibiam uma lista de "limite máximo de impurezas", o que era considerado um dado mais contundente do que a simples menção à ausência desses mesmos contaminantes ${ }^{3}$; isso se tornou possível graças ao progresso da análise titulométrica e ao desenvolvimento de uma incipiente análise instrumental. No início da década de 1950, o padrão de pureza estabelecido pela ACS passou a figurar nos rótulos dos reagentes de origem norte-americana. O controle detalhado de impurezas passou a ser parte importante do rótulo do pro-

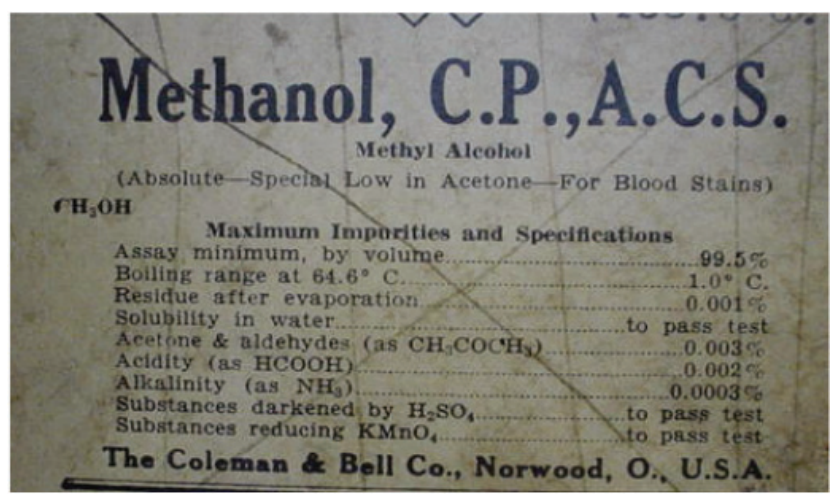

Figura 14. Metanol (1952), de origem norte-americana, exibindo no rótulo o boletim detalhado de limite de impurezas 


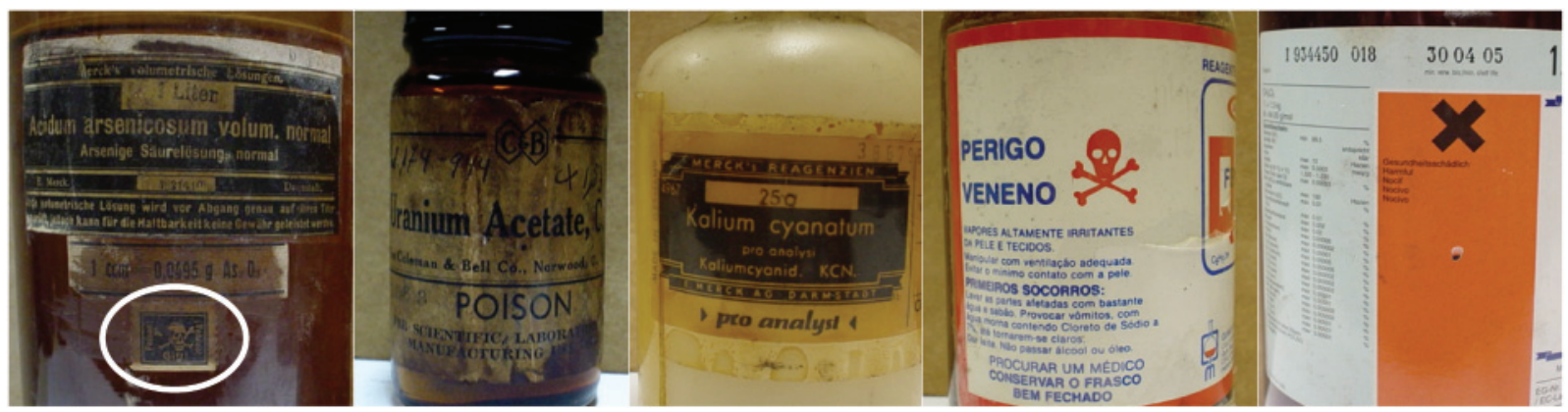

Figura 15. Reagentes venenosos e as advertências de perigo. Da esquerda para a direita: ácido arsenioso (0,1 mol L $\left.{ }^{-1}\right)$, 1929; acetato de uranila, 1944; cianeto de potássio, 1963; fenol, 1980; diclorometano, 2001

duto, especialmente quando se tratava de material destinado a aplicações especiais, sendo também viabilizado pelo grande desenvolvimento da análise instrumental a partir daquela época.

Na década de 1990, adotaram-se medidas que enquadraram os produtos químicos como quaisquer produtos farmacêuticos e alimentícios: o rótulo tinha de apresentar data de fabricação, período de validade e data limite de validade. Isso está em consonância com a Lei $8078^{20}$, a qual obriga que todo produto fabricado no país, ou importado, tenha esses dados claramente acessíveis ao consumidor.

\section{Segurança}

Outro fato interessante é o tratamento dados aos produtos comerciais quanto à periculosidade e ao manuseio. No início do século $\mathrm{XX}$, não havia qualquer menção a respeito nos rótulos dos produtos; assim, $\mathrm{NaCl}$ e $\mathrm{NaCN}$ tinham o mesmo tratamento no rótulo, isso apesar de já existirem desde antes daquela época compêndios sobre toxicidade de produtos químicos ${ }^{21,22}$. Nos anos 1920, essa postura começou a mudar com o surgimento do símbolo clássico de veneno (a caveira branca sobre fundo preto), seguido de menções como "veneno", "perigo", ou ainda um rótulo de cor negra. Essa preocupação decorreu basicamente da aplicação crescente de produtos químicos em diversas áreas além da própria química: agronomia, veterinária, geologia, farmácia, nutrição, engenharia metalúrgica, etc, onde as noções de periculosidade nem sempre eram do conhecimento pleno dos usuários ${ }^{13,21}$. O incremento dos dados de periculosidade, segurança, manuseio, transporte e primeiros socorros responde grandemente pelo aumento do tamanho e do detalhamento dos rótulos, particularmente a partir dos anos 1960 (Figura 15), sendo reconhecido como um item componente da qualidade do produto ${ }^{16}$. Hoje, este detalhamento incorporou informações e simbologias relativas a impactos ambientais.

\section{OUTROS FATOS DE INTERESSE}

\section{A medida de pH com tornassol}

Um dos exemplos mais notáveis da evolução da química comercial foi a apresentação do tornassol (litmato de cálcio), destinado à avaliação do pH de uma solução aquosa (Figura 16). De início, o reagente era sólido, sendo comercializado em grãos de formato mais ou menos esférico na cor vermelha (faixa ácida) ou azul (faixa alcalina). Era obtido a partir da calcinação de pequenos crustáceos (lackmus kaufish), particularmente abundantes na região da Holanda. A dificuldade deste produto era a avaliação do resultado para soluções coloridas. Nos anos 1930, já havia uma alternativa ao tornassol sólido: a tintura de tornassol (lackmus tinktur); a verificação do $\mathrm{pH}$ era feita gotejando-se a solução na tintura, até a cor não variar mais, situação novamente problemática no caso de soluções coradas. A

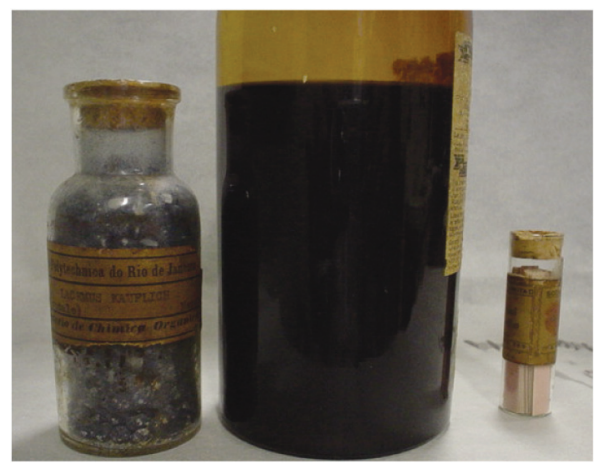

Figura 16. A apresentação do tornassol ao longo do século XX. Da esquerda para a direita: tornassol (azul) sólido, 1926; tintura (vermelha) de tornassol, 1934; papel de tornassol vermelho, 1965

impregnação dessa tintura em papel foi a grande idéia que possibilitou usar esse importante insumo de laboratório: através da difusão do líquido pelo papel se obtinha uma leitura confiável.

\section{A medida de pH com indicador universal}

O caminho seguido até a comercialização de papéis indicadores de $\mathrm{pH}$ universal foi parecido com o do tornassol. Nos anos 1920, já havia uma razoável gama de indicadores ácido-base, mas o emprego para se avaliar o pH de uma solução desconhecida era difícil por não se ter um meio sistemático de avaliação. Na década seguinte surgiram kits de soluções de indicadores únicos ou de misturas simples cujas cores eram bem delineadas segundo o pH dessas soluções. Da mesma forma que o tornassol, gotejava-se o líquido em exame no indicador até que a cor deste não variasse mais ${ }^{23}$ (da mesma forma que no caso do tornassol, esta técnica era problemática para soluções coradas). A impregnação dos indicadores em papel e o refinamento das misturas dos mesmos permitiram obter os tão conhecidos papéis de $\mathrm{pH}$ universal, bastante usados desde os anos $1950^{12}$.

\section{CONCLUSÕES}

Impulsionados por fatores comerciais, pela expansão do emprego de produtos químicos em inúmeras atividades e por obrigações legais, os rótulos mostraram uma notável evolução no tamanho e em seu detalhamento ao longo do século XX, onde três etapas podem ser identificadas: (a) a apresentação do nome do produto em vários idiomas; (b) a inclusão de um boletim de garantia relativo à ausência de impurezas, seguido por uma listagem de limites máximos desses contaminantes e (c) a inclusão de dados relativos à segurança, periculosidade, primeiros socorros e impactos ambientais.

Em paralelo, observou-se uma crescente funcionalização das 
embalagens, com a adoção de materiais que conferiam melhores características de segurança, manuseio e manutenção da qualidade do produto: (a) a substituição do vidro sódico pelo vidro neutro, e a substituição deste por materiais plásticos, sempre que possível; (b) a substituição da rolha de cortiça pela tampa rosqueada e (c) a adoção de um sistema de vedação entre a tampa e a embalagem.

Os reagentes também podem mostrar aspectos pitorescos, como a evolução da língua escrita, da denominação dos compostos químicos, a importância da obtenção de produtos de fontes naturais no início do século XX e o emprego de ensaios e técnicas analíticas hoje obsoletas, como no caso das medidas de $\mathrm{pH}$.

Observa-se hoje a continuidade do desenvolvimento de novos reagentes com grau de pureza específico para uma gama de aplicações cada vez mais diferenciadas, bem como para atender a uma rigidez crescente de legislações relacionadas à qualidade dos produtos químicos e dos ensaios em que eles são utilizados. Os conhecimentos sobre toxicologia de produtos químicos e a interação destes com o meio ambiente vêm progredindo notavelmente nos últimos anos. Tudo isso leva à premissa de que tanto o rótulo como a embalagem estarão sujeitos a novas modificações a fim de contemplar esse perfil de evolução projetado para o futuro ${ }^{24}$.

\section{AGRADECIMENTOS}

Ao Setor de Comunicação Social da Merck SA Indústrias Químicas Brasil e da Bayer S. A. pela cessão dos livros referentes à história de suas empresas.

A I. Possehl e a K. Glock (Merck KGaA, Darmstadt - Alemanha) pelas informações acerca da datação dos reagentes históricos da empresa e por toda a consultoria prestada neste campo.

À Fundação José Bonifácio (FUJB) pelo auxílio financeiro.

A G. T. Fontoura (Bayer S. A.) pelas informações prestadas sobre normas aplicadas a produtos químicos.

Ao Prof. J. M. Melo Filho (IQ/UFRJ) pelas fotografias digitais deste trabalho.

\section{REFERÊNCIAS}

1. Antunes, A. M. S.; Tese de Doutorado, Universidade Federal do Rio de Janeiro, Brasil, 1987.

2. Joannis, A.; Encyclopédie Industrielle - Traité de Chimie Organique Appliquée, Gauthier-Villards et Fils: Paris, 1896, vol. 1, p. 1-32.
3. Stephen, W. I.; Townshend, A.; Chemistry in Britain 1984, 20, 1008.

4. Possehl, I.; Modern by Tradition - The History of the ChemicalPharmaceutical Factory E. Merck, Merck: Darmstadt, 1994.

5. Normandy, A.; The Dictionaries to the Chemical Atlas, G. Knight: Londres, 1857.

6. Krauch, C.; Die Prüfung der Chemischen Reagentien auf Reinheit, Brill: Darmstadt, 1888.

7. Howard, E. D.; The Cause and Extend of the Recent Industrial Progress of Germany, Houghton Mifflin and Co: Boston, 1907.

8. Ludwig, E.; Os Alemães: Dupla História duma Nação, Livraria José Olympio Ed.: Rio de Janeiro, 1941, cap. 4.

9. Steinert, O.; En El Reino de la Química, Econ-Verlag: Dusseldorf/Viena, 1965.

10. Stein, N.; Reclames da Bayer 1911-1942, Bayer do Brasil S. A.: São Paulo, 1986.

11. White, E.; Analytical Reagents, Standards and Tests, Hopkin and Williams: Londres, 1911.

12. Ebner, F.; Lerch, L.; Da Antiga Farmácia do Anjo à Grande Empresa Químico-Farmacêutica, Merck: Darmstadt, 1968.

13. Foram contatados os departamentos comerciais de diversas empresas estrangeiras fabricantes de produtos químicos (Bayer, Merck, Riedel, Baker) os quais encaminharam as consultas sobre reagentes aos respectivos setores históricos e de documentação dessas empresas. Entre abril de 2000 e março de 2002 foram recebidos e enviados 125 correios eletrônicos contendo informações sobre a evolução dos rótulos e fragmentos de catálogos comerciais anteriores a 1921, o que permitiu documentar os reagentes fabricados antes desse ano.

14. O Proedes - Programa de Estudos e Documentação Educação e Sociedade contém todo o acervo da antiga Faculdade Nacional de Filosofia da Universidade do Brasil, donde provém grande parte do acervo examinado: http://www.cfch.ufrj.br/proedes.

15. O museu da Escola Politécnica da UFRJ contém documentos de arquivo que remontam aos tempos da Real Academia Militar, onde se pôde observar compras de reagentes para os laboratórios da antiga Escola Politécnica do Rio de Janeiro do início do século XX. http://www.engenharia.ufrj.br/ museu.

16. Hupe, K. G. M.; 75 Anos Merck no Brasil, Merck: Rio de Janeiro, 1998.

17. Billmeyer Jr., F. W.; Textbook of Polymer Science, $2^{\text {a }}$ ed., WileyInterscience: Nova Iorque, 1981

18. Santos, N. P.; Tese de Mestrado, Universidade Federal do Rio de Janeiro, Brasil, 1994.

19. Chagas, A. P.; Quim. Nova 1987, 10, 298.

20. Lei No 8078, de 11/09/1990, Diário Oficial da União, 12/09/1990.

21. Hamilton, A.; Johnstone, R.; Industrial Toxicology, Oxford University Press: Nova Iorque, 1945.

22. Jglaister, J.; Logan, D. D.; Gas Poisoning in Mining and Other Industries, Edinburgh: Nova Iorque, 1914.

23. Quintela, D. M.; Revista Syniatrica 1941, 34, 181.

24. Fontoura, G. T.; comunicação pessoal. 